\title{
Electrochemical Oxidation of Saccharose on Copper (Hydr)oxide- Modified Electrode in Alkaline Media
}

\author{
Majid JAFARIAN ${ }^{1, *}$, Mehdi RASHVAND AVEI ${ }^{1}$, Iman DANAEE ${ }^{2}$, Fereydoon GOBAL $^{3}$, \\ Mohammad G. MAHJANI ${ }^{1}$ \\ ${ }^{1}$ Department of Chemistry, K. N. Toosi University of Technology, P.O. Box 15875-4416, Tehran, Iran \\ ${ }^{2}$ Abadan Faculty of Petroleum Engineering, Petroleum University of Technology, Abadan, Iran \\ ${ }^{3}$ Department of Chemistry, Sharif University of Technology, P.O. Box 11365-8516, Tehran, Iran
}

\begin{abstract}
A stable copper (hydr)oxide-modified electrode was prepared in $0.5 \mathrm{~mol} / \mathrm{L} \mathrm{NaOH}$ solution by cyclic voltammetry in the range of -250 to $1000 \mathrm{mV}$. It can be used for electrochemical studies in the range of -250 to $1000 \mathrm{mV}$ without interfering peaks because there is no oxidation of copper. During an anodic potential sweep, the electro-oxidation of saccharose on $\mathrm{Cu}$ occurred by the formation of $\mathrm{Cu}{ }^{\mathrm{III}}$ and this reaction also occurred in the early stages of the reversed cycle until it is stopped by the negative potentials. A mechanism based on the electro-chemical generation of $\mathrm{Cu}^{\mathrm{III}}$ active sites and their subsequent consumption by saccharose was proposed, and the rate law and kinetic parameters were obtained. The charge transfer resistance from theoretical and impedance studies was used to verify the mechanism. Under chronoamperometry regimes, the reaction followed Cottrellian behavior. The transfer of up to 21 electrons was observed in further investigations of the electro-oxidation of saccharose on a (hydr)oxide $\mathrm{Cu}$ rotating disk electrode.
\end{abstract}

Key words: saccharose; copper (hydr)oxide; equivalent circuit; electrocatalytic oxidation; mechanism

CLC number: O643 Document code: A

Carbohydrates that comprise more than $80 \%$ of available biomass are the most abundant compounds. The electrochemical detection of carbohydrates, which is important in many medical, biological, and industrial applications, is simple, selective, and cheap [1,2], and is an alternative to spectroscopic methods used in high performance liquid chromatography (HPLC) and flow injection analysis (FIA) experiments. Many comprehensive investigations have been carried out during the past decades on the electrocatalytic oxidation of alcohols, poly-alcohols, and carbohydrates on different catalytic metal electrodes that were aimed at the development of sensors and fuel cells $[3,4]$, but only a few of these have studied saccharose electro-oxidation [5].

The electro-oxidation of carbohydrates have been studied on a variety of metallic [3,6-10], metal oxide [11-13], and metal complex [14] electrodes. Luo et al. [15] employed cyclic voltammetry, hydrodynamic voltammetry, coulometry, and NMR to characterize the oxidation of glucose and related polyalcohols on a copper electrode. Studies by Miller [16] have defined the oxidation states of $\mathrm{Cu}$ in alkaline solutions by assigning five peaks to three major single-electron processes involving $\mathrm{Cu} / \mathrm{Cu}^{\mathrm{I}}, \mathrm{Cu}^{\mathrm{I}} / \mathrm{Cu}^{\mathrm{II}}$, and $\mathrm{Cu}^{\mathrm{II}} / \mathrm{Cu}^{\mathrm{III}}$ transitions in the cyclic voltammogram of a copper electrode. De Chialvo and co-workers [17] showed that there are soluble species associated with different oxidation states of $\mathrm{Cu}$, which makes a study involving the electro-oxidation and electroreduction of $\mathrm{Cu}$ in alkaline media very complex. They suggested the presence of $\mathrm{Cu}, \mathrm{Cu}_{\text {ads }}$, $\mathrm{Cu}_{\text {ads }} \mathrm{OH}, \mathrm{Cu}_{2} \mathrm{O}$, and $\mathrm{Cu}_{2 \text { ads }} \mathrm{O}$ on the surface of $\mathrm{Cu}^{\mathrm{I}}$, while in solution, some other species were postulated to be present.

It can be suggested that the formation of a stable layer of copper (hydr)oxide on the surface of a copper electrode can protect the electrode from corrosion so that there are no oxidation peaks of copper in this case. This idea was applied in this work to study the electro-oxidation of saccharose with the aim to elucidate its mechanism and derive the kinetic parameters of the process.

\section{Experimental}

Sodium hydroxide and saccharose used were analytical grade from Merck. They were used without further purification. All solutions were prepared with doubly distilled water.

Electrochemical studies were carried out in a conventional three electrode cell powered by an electrochemical system comprising a EG\&G Model 273A potentiostat/galvanostat and Solartron Model 1255 frequency re-

Received date: 29 May 2010.

*Corresponding author. Tel: +98-21-22853551; Fax: +98-21-22853650; E-mail: mjafarian@kntu.ac.ir

Foundation item: Supported by K. N. Toosi University of Technology.

English edition available online at ScienceDirect (http://www.sciencedirect.com/science/journal/18722067). 
sponse analyzer. The system was controlled by a PC using M270, M352, M398, and Zplot/Zview commercial softwares and a GPIB interface. The frequency range of 100 $\mathrm{kHz}$ to $15 \mathrm{mHz}$ and modulation amplitude of $5 \mathrm{mV}$ were employed for impedance measurements. A rotating electrode system (EG\&G model 1636) was also employed. A saturated $\mathrm{Ag} / \mathrm{AgCl}$ electrode and a Pt wire were used as the reference and counter electrodes, respectively. Cylindrical copper bars with the purity of $99.9 \%$ were fitted into Teflon that exposed circular areas of copper of diameters 5 and 4 $\mathrm{mm}$ to prepare the rotating disk and working electrodes, respectively. The surface of the electrode was mechanically polished with 2500 grit sand paper and then with $0.05 \mu \mathrm{m}$ $\alpha$-alumina powder prior to all experiments. The polished surfaces were rinsed with doubly distilled water prior to use. All measurements were carried out at $(298 \pm 2) \mathrm{K}$.

\section{Results and discussion}

Figure 1(a) presents a cyclic voltammogram of copper in $0.5 \mathrm{~mol} / \mathrm{L} \mathrm{NaOH}$ solution in the range of -900 to $1000 \mathrm{mV}$ vs. $\mathrm{Ag} / \mathrm{AgCl}$ recorded at a potential sweep rate of $10 \mathrm{mV} / \mathrm{s}$. The voltammogram is similar to the ones reported in the literature $[18,19,20]$ and consists of well defined peaks in both the anodic and cathodic half cycles. On comparing our results with those in the literature, the peaks can be readily assigned. Peak Ia is due to the $\mathrm{Cu} / \mathrm{Cu}^{\mathrm{I}}$ redox couple in reac-
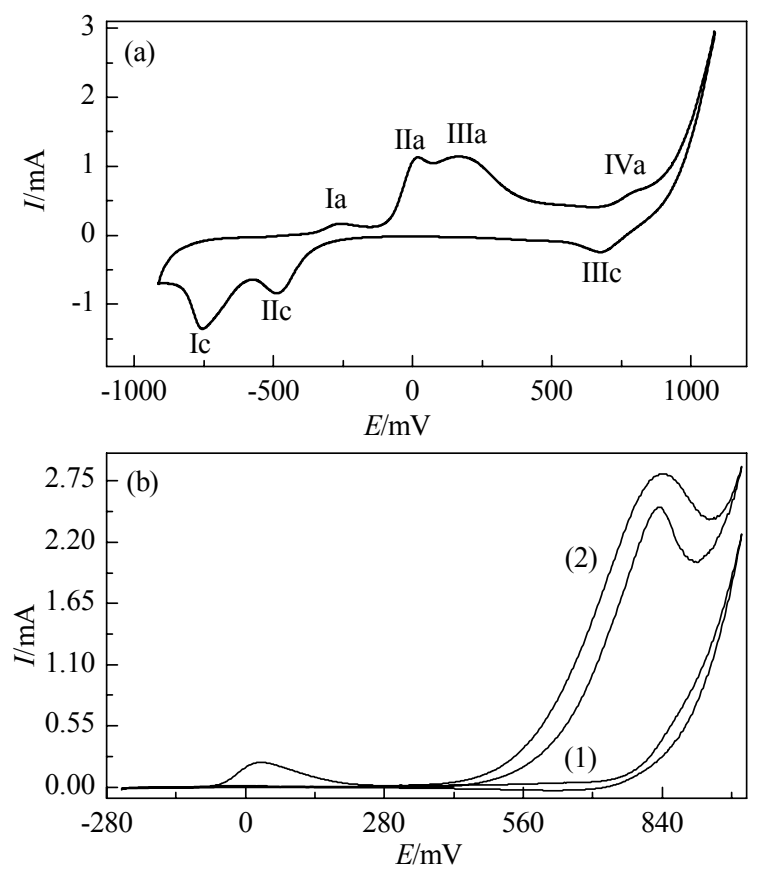

Fig. 1. Cyclic voltammograms of copper electrode in $0.5 \mathrm{~mol} / \mathrm{L}$ $\mathrm{NaOH}$ solution, scanning at $10 \mathrm{mV} / \mathrm{s}$ in the positive direction from an initial potential of -900 to $1000 \mathrm{mV}$ (a) and -250 to $1000 \mathrm{mV}$ (b) in the absence (1) and presence (2) of $0.02 \mathrm{~mol} / \mathrm{L}$ saccharose. tions (1) and (2), in which $\mathrm{Cu}$ is converted to $\mathrm{Cu}_{2} \mathrm{O}$ in alkaline solution [21]:

$$
\begin{gathered}
\mathrm{Cu}+\mathrm{OH}^{-} \rightarrow \mathrm{CuOH}+\mathrm{e} \\
2 \mathrm{CuOH} \rightleftarrows \mathrm{Cu}_{2} \mathrm{O}+\mathrm{H}_{2} \mathrm{O}
\end{gathered}
$$

Peak IIa involves the transitions $\mathrm{Cu} / \mathrm{Cu}^{\mathrm{II}}$ and $\mathrm{Cu}^{\mathrm{I}} / \mathrm{Cu}^{\mathrm{II}}$ in the following electrode processes [22]:

$$
\begin{gathered}
\mathrm{Cu}+2 \mathrm{OH}^{-} \rightarrow \mathrm{Cu}(\mathrm{OH})_{2}+2 \mathrm{e} \\
\mathrm{Cu}_{2} \mathrm{O}+\mathrm{H}_{2} \mathrm{O}+2 \mathrm{OH}^{-} \rightarrow 2 \mathrm{Cu}(\mathrm{OH})_{2}+2 \mathrm{e} \\
\mathrm{Cu}(\mathrm{OH})_{2} \rightleftarrows \mathrm{CuO}+\mathrm{H}_{2} \mathrm{O}
\end{gathered}
$$

Peak IIIa is due to the formation of soluble compounds in the redox reaction

$$
\mathrm{Cu}+3 \mathrm{OH}^{-} \rightarrow \mathrm{HCuO}_{2}^{-}+\mathrm{H}_{2} \mathrm{O}+2 \mathrm{e}
$$

and the dissolution equilibrium [19]:

$$
\mathrm{Cu}(\mathrm{OH})_{2}+2 \mathrm{OH}^{-} \rightleftarrows \mathrm{CuO}_{2}^{2-}+2 \mathrm{H}_{2} \mathrm{O}
$$

Three reduction waves observed in the course of the cathodic scans were assigned to the reduction of $\mathrm{Cu}^{\text {III }}$ to $\mathrm{Cu}^{\text {II }}$ (peak IIIc), $\mathrm{Cu}^{\mathrm{II}}$ to $\mathrm{Cu}^{\mathrm{I}}$ (IIc), and $\mathrm{Cu}^{\mathrm{I}}$ to $\mathrm{Cu}$ (peak Ia) [19]. Also, an anodic peak, IVa, just before the onset of the anodic decomposition edge of the solvent was observed. This peak was assigned to $\mathrm{Cu}^{\mathrm{III}}$ species formed by reactions (8) and (9) at high hydroxide concentration [21,22]:

$$
\begin{gathered}
\mathrm{Cu}(\mathrm{OH})_{2}+2 \mathrm{OH}^{-} \rightleftarrows \mathrm{CuO}_{2}^{-}+\mathrm{H}_{2} \mathrm{O}+\mathrm{e} \\
2 \mathrm{CuO}+2 \mathrm{OH}^{-} \rightleftarrows \mathrm{Cu}_{2} \mathrm{O}_{3}+\mathrm{H}_{2} \mathrm{O}+\mathrm{e}
\end{gathered}
$$

Figure 1(b) presents the voltammograms started at different cathodic potential limits. The oxidation peaks of copper were present in all potential ranges, which made this electrode difficult to use in many electrochemical studies. If a (hydr)oxide layer was stabilized on the copper electrode, it can protect the electrode from corrosion so that the interfering peaks due to the oxidation of copper would not appear.

Figure 2 shows repeated cyclic voltammograms recorded for the copper electrode under the above conditions in the potential range of -250 to $1000 \mathrm{mV}$. In the first cycle the oxidation peaks of copper were present but in the following

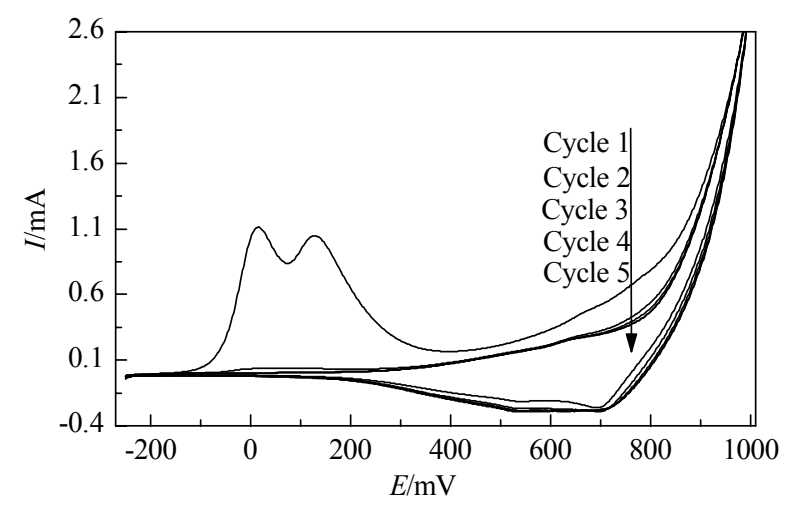

Fig. 2. Repeated cyclic voltammograms of a copper electrode in the potential range of -250 to $1000 \mathrm{mV}$ in $0.5 \mathrm{~mol} / \mathrm{L} \mathrm{NaOH}$. Potential sweep rate was $100 \mathrm{mV} / \mathrm{s}$. 
cycles, they have disappeared and a clean potential domain spanning nearly $1000 \mathrm{mV}$ was obtained. This indicated that an irreversible electrochemical transformation had taken place during the first cycle and a stable layer of hydr(oxide) was formed on the surface of the electrode that protected the electrode from corrosion. After this, this electrode can be used for electrochemical studies in the potential range of -250 to $1000 \mathrm{mV}$ without any interference by the peaks from the oxidation of the underlying copper. The surface coverage of the copper hydr(oxide) layer $(\Gamma)$ was calculated using the equation [23]:

$$
\Gamma=\frac{Q}{n F A}
$$

where $Q$ was the charge obtained by integrating the area under the anodic wave of the cyclic voltammogram and other symbols have their usual meanings. The surface coverage of the copper hydr(oxide) layer on the modified electrode was found to be $1.18 \times 10^{-7} \mathrm{~mol} / \mathrm{cm}^{2}$.

Marioli et al. [21] have suggested a different route for the oxidation of carbohydrates on copper oxide from a remarkable diminution of the copper(II) oxide peak observed upon adding the substrate. The electro-oxidation of saccharose occurs not only in the anodic but also continues into the initial stages of the cathodic half cycle (Fig. 1(2)). Assuming that saccharose molecules adsorb on $\mathrm{Cu}^{\mathrm{II}}$ sites at these potentials and oxidized $\mathrm{Cu}^{\mathrm{II}}$ to $\mathrm{Cu}^{\mathrm{III}}$ sites, the number of $\mathrm{Cu}^{\mathrm{II}}$ sites available to the sugar would decrease in the course of an anodic potential sweep. The decrease would be further accentuated by the persistent (poisonous) adsorption of the intermediates. The anodic current would thus pass through a maximum as the potential is anodically swept. In the reverse half cycle, the electro-oxidation of saccharose continues and its corresponding current goes through a maximum due to the regeneration of $\mathrm{Cu}^{\mathrm{II}}$ surface species that are the active sites for the adsorption of saccharose. Thus, the rate of saccharose/intermediates oxidation, as reflected by the anodic current in the cathodic half cycle, drops as the unfavorable cathodic potentials are approached.

Figure 3 presents the effect of saccharose concentration on the cyclic voltammograms of the modified copper electrode. Increasing the concentration causes a proportional enhancement of the irreversible oxidation peak of saccharose, which is shown in the inset.

On the basis of our results, the following mechanism and kinetics can be proposed for the electro-oxidation of saccharose on the copper (hydr)oxide modified electrode. The redox transition of the copper species,

$$
\mathrm{Cu}(\mathrm{II}) \underset{k_{-1}(E)}{\stackrel{k_{1}(E)}{\rightleftarrows}} \mathrm{Cu}(\mathrm{III})+\mathrm{e}
$$

is followed by the oxidation of saccharose:

$$
\mathrm{Cu}(\mathrm{III})+\text { Saccharose } \stackrel{k_{2}(E)}{\longrightarrow} \text { Intermediate }+\mathrm{Cu} \text { (II) (12) }
$$

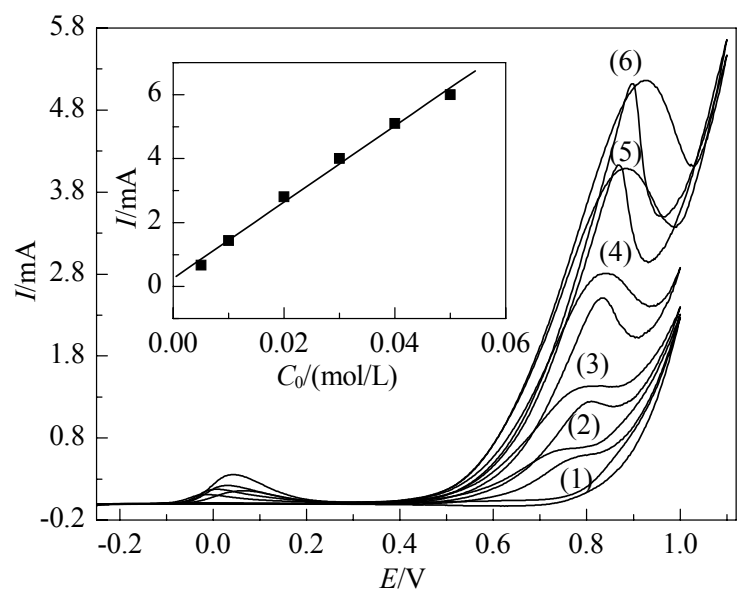

Fig. 3. Cyclic voltammograms of copper (hydr)oxide-modified electrode in $0.5 \mathrm{~mol} / \mathrm{L} \mathrm{NaOH}$ solution in the presence of different concentrations of saccharose. (1) 0 ; (2) $0.005 \mathrm{~mol} / \mathrm{L}$; (3) $0.01 \mathrm{~mol} / \mathrm{L}$; (4) 0.02 $\mathrm{mol} / \mathrm{L}$; (5) $0.03 \mathrm{~mol} / \mathrm{L}$; (6) $0.04 \mathrm{~mol} / \mathrm{L}$. The potential sweep rate is 10 $\mathrm{mV} / \mathrm{s}$. Inset: dependence of the anodic current electro-oxidation on saccharose concentration.

The intermediate is further oxidized to the product, glycolic acid, and formic acid [5], through similar mediated electro-oxidation process:

$$
\mathrm{Cu}(\mathrm{III})+\text { Intermediate } \stackrel{k_{3}(E)}{\longrightarrow} \text { Product }+\mathrm{Cu}(\mathrm{II})(13)
$$

In the above sequence of reactions, $k_{1}$ and $k_{-1}$ are potential dependent and have the form:

$$
\begin{gathered}
k_{1}(E)=k_{1}^{0} \exp \left[\alpha n F\left(E-E_{0} / R T\right)\right. \\
k_{-1}(E)=k_{-1}^{0} \exp \left[(\alpha-1) n F\left(E-E_{0}\right) / R T\right]
\end{gathered}
$$

where $k^{0}$ is the chemical rate constants measured at $\left(E-E_{0}\right)$ vs. $\mathrm{Ag} / \mathrm{AgCl}=0$, and $\alpha$ is the anodic symmetry factor. The rate laws for reactions (11) and (12) have the following forms:

$$
\begin{gathered}
v_{(11)}=k_{1} \Gamma \theta_{\mathrm{II}}-k_{-1} \Gamma \theta_{\mathrm{III}} \\
v_{(12)}=k_{2} \Gamma \theta_{\mathrm{III}} C_{s}
\end{gathered}
$$

where the $\theta$ is the fractional coverages of different copper valance states, and $C_{s}$ is the bulk concentration of saccharose. With only the 2 and 3 valence states of copper,

$$
\theta_{\mathrm{II}}+\theta_{\mathrm{III}}=1
$$

The rates of change of their coverages are:

$$
\begin{gathered}
\mathrm{d} \theta_{\mathrm{II}} / \mathrm{d} t=-\mathrm{d} \theta_{\mathrm{III}} / \mathrm{d} t=-k_{1} \theta_{\mathrm{II}}+k_{-1} \theta_{\mathrm{III}}+k_{2} \theta_{\mathrm{III}} C_{s}+k_{3} \theta_{\mathrm{III}} C_{i} \\
\mathrm{~d} C_{i} / \mathrm{d} t=k_{2} \theta_{\mathrm{II}} C_{s}-k_{3} \theta_{\mathrm{III}} C_{i}
\end{gathered}
$$

where $C_{i}$ is the concentration of the oxidation reaction intermediate. Assuming that the steady state approximation is valid,

$$
\begin{gathered}
\mathrm{d} \theta_{\mathrm{II}} / \mathrm{d} t=-\mathrm{d} \theta_{\mathrm{III}} / \mathrm{d} t=0 \\
\mathrm{~d} C_{i} / \mathrm{d} t=0
\end{gathered}
$$

The values of the coverages are therefore

$$
\theta_{\mathrm{II}}=\left(k_{-1}+2 k_{2} C_{s}\right) /\left(k_{1}+k_{-1}+2 k_{2} C_{s}\right)
$$




$$
\theta_{\mathrm{III}}=k_{1} /\left(k_{1}+k_{-1}+2 k_{2} C_{s}\right)
$$

Subsequently:

$$
v_{(11)}=\left(2 k_{1} \Gamma k_{2} C_{s}\right) /\left(k_{1}+k_{-1}+2 k_{2} C_{s}\right)
$$

On the basis of this rate equation, the Faradic current will be

$$
i_{f}=\left(2 F A k_{1} \Gamma k_{2} C_{s}\right) /\left(k_{1}+k_{-1}+2 k_{2} C_{s}\right)
$$

and the corresponding charge transfer resistance is

$$
\begin{gathered}
R_{c t}=\left(\mathrm{d} i_{f} / \mathrm{d} E\right)^{-1}=\left(k_{1}+k_{-1}+2 k_{2} C_{s}\right) / \\
{\left[2 F A \Gamma k_{2} C_{s} k_{1}\left(2 \alpha F k_{2} C_{s} / R T+k_{-1} F / R T\right)\right]}
\end{gathered}
$$

Eq. (27) can be used for the calculation of the rate constants and for testing the validity of the kinetics and mechanism. This will be taken up after the chronoamperometry and impedance measurement have been discussed.

Figure 4(a) presents the double-step chronoamperograms that were recorded by setting the working electrode poten-
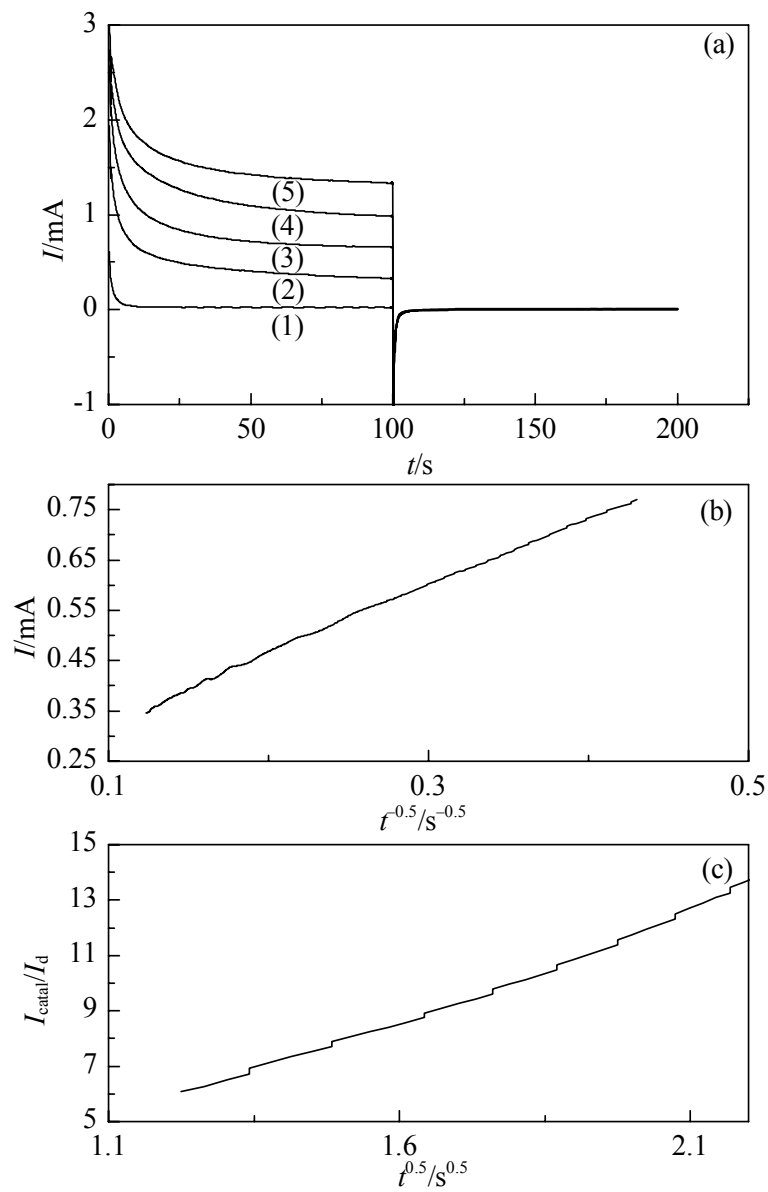

Fig. 4. (a) Double-step chronoamperograms of copper (hydr)oxide modified electrode in $0.5 \mathrm{~mol} / \mathrm{L} \mathrm{NaOH}$ solution containing saccharose of different concentrations. (1) 0 ; (2) $0.005 \mathrm{~mol} / \mathrm{L}$; (3) $0.01 \mathrm{~mol} / \mathrm{L}$; (4) $0.02 \mathrm{~mol} / \mathrm{L}$; (5) $0.03 \mathrm{~mol} / \mathrm{L}$. Potential steps were $730 \mathrm{mV}$ for oxidation and $0 \mathrm{mV}$ for reduction. (b) The plot of net current of the chronoamperogram of copper (hydr)oxide-modified electrode in $0.5 \mathrm{~mol} / \mathrm{L} \mathrm{sac}-$ charose (obtained by subtracting the background current using the point-by-point subtracting method) vs. $t^{-0.5}$. (c) Dependence of $I_{\text {catal }} / I_{\mathrm{d}}$ on $t^{0.5}$ derived from the data of chronoamperograms of (1) and (2) in (a). tials to desired values in the absence and in the presence of saccharose in $0.5 \mathrm{~mol} / \mathrm{L} \mathrm{NaOH}$ solution. The applied potential steps were 730 and $0 \mathrm{mV}$ vs. $\mathrm{Ag} / \mathrm{AgCl}$, respectively. The plotting of the net current with respect to minus square root of time gave a linear plot, Fig. 4(b), which indicated the dominance of a diffusion controlled process. The transition current was obviously due to the oxidation of saccharose by $\mathrm{Cu}^{\text {III }}$ species, which was substantiated by the results on increasing the concentration of saccharose. Also, as the electrolysis potential was stepped down to $0 \mathrm{mV}$ vs. $\mathrm{Ag} / \mathrm{AgCl}$, no significant current was obtained, which indicated the irreversibility of the process. Chronoamperometry can also be used for the evaluation of the catalytic rate constant, according to [24], by

$$
I_{\text {catal }} / I_{\mathrm{d}}=\lambda^{0.5}\left[\pi^{0.5} \operatorname{erf}\left(\lambda^{0.5}\right)+\exp (-\lambda) / \lambda^{0.5}\right]
$$

The argument of the error function, $\lambda$, equals $k^{\prime} C_{s} t$ with $k^{\prime}$, and $C_{s}$ and $t$ are the apparent rate constant of saccharose consumption, the bulk concentration of saccharose and the time of measuring $I_{\text {catal }}$. For $\lambda>1.5, \operatorname{erf}\left(\lambda^{0.5}\right)$ almost equals unity and the above equation reduces to:

$$
I_{\text {catal }} / I_{\mathrm{d}}=\pi^{0.5} \lambda^{0.5}
$$

From the slope of the $I_{\text {catal }} / I_{\mathrm{d}}$ vs. $t^{0.5}$ plot, the value of $k^{\prime}$ was calculated to be $4.3 \times 10^{6} \mathrm{~cm}^{3} /(\mathrm{mol} \cdot \mathrm{s})$. This is shown in Fig. 4(c). It should be pointed out that $k^{\prime}$ is either $k_{2}$ or $k_{3}$, whichever is smaller.

Figure 5 illustrates the Nyquist diagrams of the copper (hydr)oxide-modified electrodes recorded at $730 \mathrm{mV}$ vs. $\mathrm{Ag} / \mathrm{AgCl}$ dc-offset for concentrations of $0.005-0.05 \mathrm{~mol} / \mathrm{L}$ saccharose in $0.5 \mathrm{~mol} / \mathrm{L} \mathrm{NaOH}$ solution. The Nyquist diagrams consist of two slightly depressed capacitive semicircles at the high and low frequencies. The depressed semicircle in the high frequency region is related to the adsorption of (hydr)oxide copper layer on the electrode surface. The low frequency semicircle is related to the combination

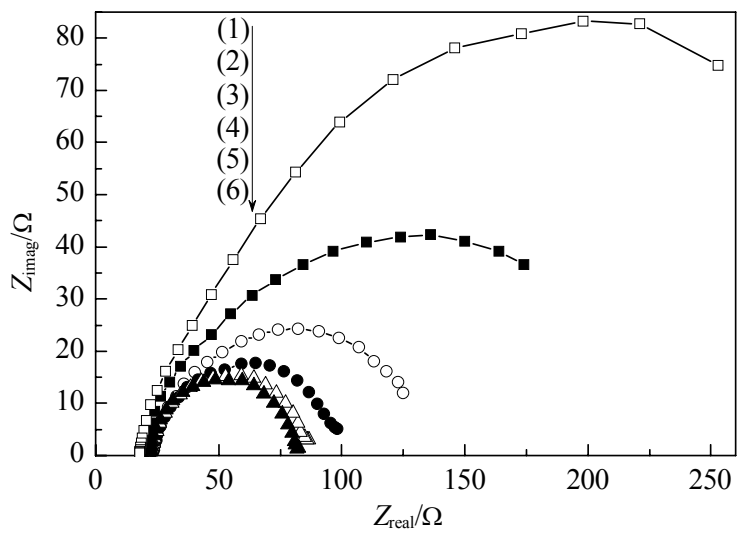

Fig. 5. Nyquist diagrams of copper (hydr)oxide-modified electrode in the 0.005 (1), 0.01 (2), 0.02 (3), 0.03 (4), 0.04 (5), and $0.05 \mathrm{~mol} / \mathrm{L}$ (6) saccharose in $0.5 \mathrm{~mol} / \mathrm{L} \mathrm{NaOH}$ solution. Direct current potential is $730 \mathrm{mV}$. 
of charge transfer resistance and the double layer capacitance.

The equivalent circuit compatible with these results is presented in Scheme 1. In this electrical equivalent circuit, $R_{\mathrm{s}}, Q_{\mathrm{dl}}$, and $R_{\mathrm{ct}}$ represent solution resistance, a constant phase element corresponding to the double-layer capacitance, and the charge-transfer resistance associated with the oxidation of the saccharose, respectively. The chargetransfer resistance of the electrode reaction is the only circuit element that has a simple physical meaning, which describes how fast the rate of charge transfer during electrocatalytic oxidation changes with the electrode potential or bulk concentration of saccharose in solution. $Q_{\mathrm{ad}}$ and $R_{\mathrm{ad}}$ are electrical elements related to the adsorption of (hydr)oxide copper layer. In order to obtain a satisfactory fit of the Nyquist diagrams, it was necessary to replace the double-layer capacitance with a constant phase element in the equivalent circuit. The most widely accepted explanation for the presence of this distributed element and the appearance of depressed semi-circles in the Nyquist plots is microscopic roughness, which cause an inhomogeneous distribution in the solution resistance and in the double-layer capacitance [25]. It should be added that the diffusion process observed during the oxidation process (Fig. 4(b)) would have ap-

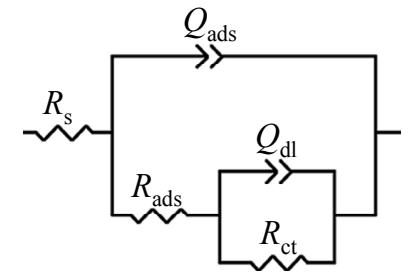

Scheme 1. Equivalent circuits of the Nyquist diagrams in Fig. 5.

peared at very low frequencies with a high time constant. It did not appear in the sweeping frequency range in the $\mathrm{Ny}$ quist diagrams.

To corroborate the equivalent circuit, the experimental data were fitted to the equivalent circuit and the circuit elements were obtained. Table 1 shows the values of the equivalent circuit elements obtained by fitting the experimental results for different concentrations of saccharose. The goodness of the fit can be judged by the estimated relative errors presented in parentheses. In Table $1, Q$ and $n$ are the CPE impedance coefficient and exponent, respectively. As can be seen from Table 1, increasing the saccharose concentration decreased the diameters of the second semicircles whereas there were no corresponding changes in the first semicircles.

Table 1 Values of the equivalent circuit elements obtained by fitting the experimental results for saccharose in the Nyquist plots in Fig. 5 and relative errors

\begin{tabular}{cccccccc}
\hline$C_{0} /(\mathrm{mol} / \mathrm{L})$ & $R_{\mathrm{s}} / \Omega$ & $R_{\mathrm{ads}} / \Omega$ & $Q_{\mathrm{ads}} /\left(10^{4} \mathrm{~F}\right)$ & $R_{\mathrm{ct}} / \Omega$ & $Q_{\mathrm{dl}} /\left(10^{3} \mathrm{~F}\right)$ & $n_{1}$ \\
\hline 0.005 & $17.87(0.34 \%)$ & $27.56(1.02 \%)$ & $2.99(0.81 \%)$ & $320.7(1.31 \%)$ & $2.23(1.45 \%)$ & $0.87(0.85 \%)$ & $0.54(1.28 \%)$ \\
0.01 & $19.54(0.43 \%)$ & $25.76(0.94 \%)$ & $2.58(1.54 \%)$ & $189.6(0.77 \%)$ & $3.25(2.18 \%)$ & $0.84(2.17 \%)$ & $0.47(1.62 \%)$ \\
0.02 & $22.99(0.52 \%)$ & $25.72(2.21 \%)$ & $2.51(1.97 \%)$ & $89.55(0.87 \%)$ & $2.91(1.05 \%)$ & $0.82(2.77 \%)$ & $0.52(2.92 \%)$ \\
0.03 & $23.21(0.61 \%)$ & $29.61(1.59 \%)$ & $2.82(2.04 \%)$ & $47.89(3.75 \%)$ & $2.79(1.94 \%)$ & $0.79(2.84 \%)$ & $0.59(1.59 \%)$ \\
0.04 & $22.48(0.54 \%)$ & $33.54(2.55 \%)$ & $2.64(1.54 \%)$ & $30.02(1.67 \%)$ & $2.40(2.55 \%)$ & $0.78(2.05 \%)$ & $0.69(1.88 \%)$ \\
0.05 & $21.47(0.67 \%)$ & $34.82(2.68 \%)$ & $2.61(1.69 \%)$ & $25.24(1.91 \%)$ & $2.07(3.43 \%)$ & $0.77(2.27 \%)$ & $0.73(2.43 \%)$ \\
\hline
\end{tabular}

The saccharose concentration dependency of $R_{\mathrm{ct}}$ is presented in Fig. 6, where an initial sharp drop changed to a very slow drop as the concentration of saccharose was increased. The results were fitted to Eq. (27) to estimate the values of the rate constant. From the fitted equation and assuming $\alpha=1$, the values of the rate constants were $k_{1}=$ $2.2 \times 10^{-8} \mathrm{~s}^{-1}$ and $k_{2}=2.8 \times 10^{5} \mathrm{~cm}^{3} /(\mathrm{mol} \cdot \mathrm{s})$.

In order to evaluate the performance of the copper (hydr)oxide-modified copper electrode as an amperometric sensor for carbohydrate detection, we studied the electro-oxidation ability of saccharose in alkaline solution. A typical hydrodynamic chronoamperometric response was obtained by the progressive addition of saccharose to $10 \mathrm{ml}$ of a $0.5 \mathrm{~mol} / \mathrm{L} \mathrm{NaOH}$ solution under continuous stirring at $300 \mathrm{r} / \mathrm{min}$. The electrode response time was fast for the different saccharose concentrations, giving stable currents in a few seconds. The anodic current for the different concentrations of saccharose were recorded to get the typical analyti- cal curve. The limits of detection (LOD) and quantitation (LOQ) of the procedure were calculated according to the 3S.D. $/ m$ and 10 S.D. $/ m$ criteria, respectively, where S.D. is

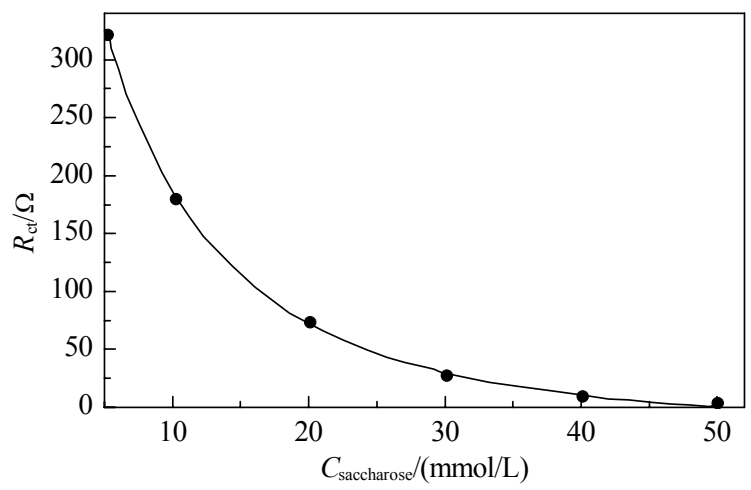

Fig. 6. Dependence of $R_{\mathrm{ct}}$ on saccharose concentration derived from the Nyquist diagrams $(\bullet)$ in Fig. 5, which were compared with theoretical equation (-). 
the standard deviation of the intercept and $m$ is the slop of the calibration curves [26]. In this curve (illustrated in Fig. 7 ), the anodic current at the sensor ranged from $4.995 \times 10^{-4}$ to $5.928 \times 10^{-3} \mathrm{~mol} / \mathrm{L}$ with a detection limit of $1.407 \times 10^{-4}$ $\mathrm{mol} / \mathrm{L}$ and a quantitation limit of $4.693 \times 10^{-4} \mathrm{~mol} / \mathrm{L}$.

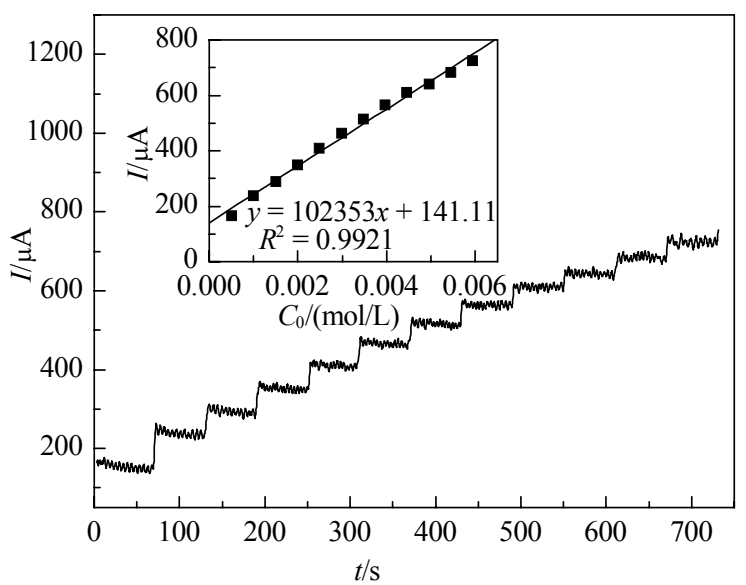

Fig. 7. Chronoamperometric response of the copper-modified electrode in $0.5 \mathrm{~mol} / \mathrm{L} \mathrm{NaOH}$ for successive addition $10 \mu \mathrm{l}$ of $0.5 \mathrm{~mol} / \mathrm{L}$ saccharose solution. The inset is the relationship of the current response of the sensor with the saccharose concentration. Applied working potential $0.73 \mathrm{~V}$ vs. $\mathrm{Ag} / \mathrm{AgCl}$.

Using the method described, it is possible to determine both the number of electrons transferred $(n)$ and the apparent heterogeneous electron transfer rate constant $(k)$, by using Koutecky-Levich plots (Eq. (30) [27]) for each carbohydrate.

$$
\begin{gathered}
1 / I=1 / I_{k}+1 / I_{d}=\left(n k F A C_{0}^{*}\right)^{-1}+ \\
\left(0.62 n F A C_{0}^{*} D_{0}^{2 / 3} v^{-1 / 6} \omega^{1 / 2}\right)^{-1}
\end{gathered}
$$

Figure 8 shows the voltammograms of $0.008 \mathrm{~mol} / \mathrm{L} \mathrm{sac}-$ charose at rotating copper (hydr)oxide-modified electrode in

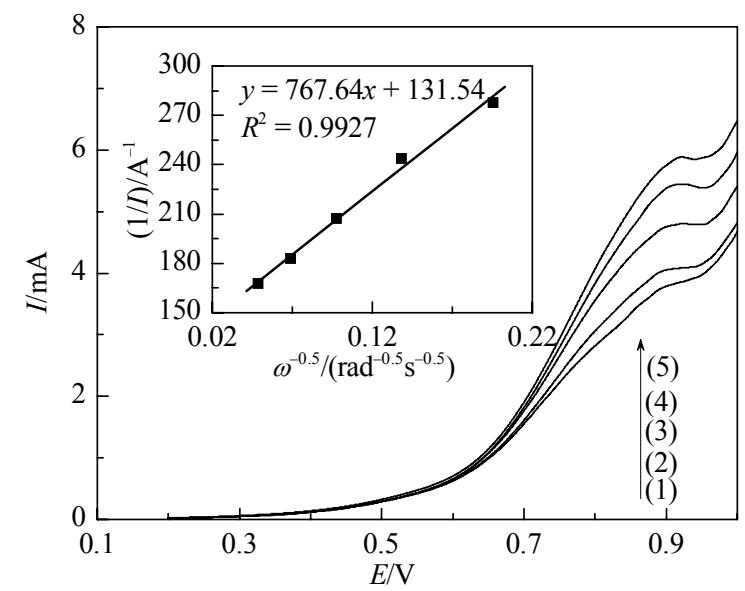

Fig. 8. Rotating voltammogram of $0.008 \mathrm{~mol} / \mathrm{L}$ saccharose at copper (hydr)oxide-modified electrode in $0.5 \mathrm{~mol} / \mathrm{L} \mathrm{NaOH}$ with $\omega=250$ (1), 500 (2), 1000 (3), 2000 (4), and $4000 \mathrm{r} / \mathrm{min}$ (5). The potential sweep rate is $10 \mathrm{mV} / \mathrm{s}$. Inset: Plot of $1 / I$ versus $w^{-0.5}$.
$0.5 \mathrm{~mol} / \mathrm{L} \mathrm{NaOH}$ with different rotation speeds. As expected a linear relationship was observed between $1 / I$ and $w^{-0.5}$ Values of the kinematic viscosity $(v)$ and diffusion coefficient $\left(D_{0}\right)$ were obtained from the literature [28]. The number of electrons transferred for one molecule of saccharose was found to be $21.7 \pm 2.1$. According to the literature, the number of transferred electrons during the carbohydrate oxidation is very high due to the formation of different intermediates, which are also oxidized at the highly catalytic copper hydroxide surface. The rate constant was calculated and was around $2.3 \times 10^{-3} \mathrm{~cm} / \mathrm{s}$.

\section{Conclusions}

This work presented the preparation of copper (hydr)oxide-modified copper electrode in $0.5 \mathrm{~mol} / \mathrm{L} \mathrm{NaOH}$ solution by cycling the potential in the range of -250 to $1000 \mathrm{mV}$. This layer protected the electrode from corrosion and thus there were no interfering oxidation peaks of copper. The modified electrode was successfully used for studying the electrocatalytic oxidation of saccharose. The electrode was electro-catalytically active around $0.7 \mathrm{mV}$ vs. $\mathrm{Ag} / \mathrm{AgCl}$ and the electro-oxidation occurred through a mediated electron transfer mechanism. Using cyclic voltammetry, chronoamperometry, impedance spectroscopy, and rotating disk electrode experiment, the kinetic parameters of saccharose oxidation were determined.

\section{References}

1 Johnson D C, Weber S G, Bond A M, Wightman R M, Shoup R E, Krull I S. Anal Chim Acta, 1986, 180: 187

2 Kissinger P T. J Chromatogr B, 1989, 488: 31

3 Vassilyev Y B, Khazova O A, Nikolaeva N N. J Electroanal Chem, 1985, 196: 105

4 Ocon P, Alonso C, Celdran R, Gonzalez-Velasco J. J Electroanal Chem, 1986, 206: 179

5 Parpot P, Kokoh K B, Beden B, Lamy C. Electrochim Acta, 1993, 38: 1679

6 de Mele M F L, Videla H A, Arvia A J. Bioelectrochem Bioenerg, 1983, 10: 239

7 Neuburger G G, Johnson D C. Anal Chem, 1987, 59: 150

8 Prabhu S V, Baldwin R P. Anal Chem, 1989, 61: 852

9 Luo P F, Zhang F Z, Baldwin R P. Anal Chim Acta, 1991, 244: 169

10 Ye J, Baldwin R P. J Chromatogr A, 1994, 687: 141

11 Reim R E, Van Effen R M. Anal Chem, 1986, 58: 3203

12 Zhang X, Chan K Y, Tseung A C C. J Electroanal Chem, 1995, 386: 241

13 Wang J, Taha Z. Anal Chem, 1990, 62: 1413

14 Santos L M, Baldwin R P. Anal Chem, 1987, 59: 1766

15 Luo M Z, Baldwin R P. J Electroanal Chem, 1995, 387: 87

16 Miller B. J Electrochem Soc, 1969, 116: 1675 
17 de Chialvo M R G, Marchiano S L, Arvia A J. J Appl Electrochem, 1984, 14: 165

18 Pyun C H, Park S M. J Electrochem Soc, 1986, 133: 2024

19 Colon L A, Dadoo R, Zare R N. Anal Chem, 1993, 65: 476

20 Mannino S, Rossi M, Ratti S. Electroanalysis, 1991, 3: 711

21 Marioli J M, Kuwana T. Electrochim Acta, 1992, 37: 1187

22 Torto N, Ruzgas T, Gorton L. J Electroanal Chem, 1999, 464: 252

23 Jayasri D, Sriman Narayanan S. J Hazard Mater, 2007, 144: 348

24 Bard A J, Faulkner L R. Electrochemical Methods: Funda- mental and Applications. New York: John Wiley \& Sons, 2001. 471

25 Maritan A, Toigo F. Electrochim Acta, 1990, 35: 141

26 Miller J C, Miller J N. Statistics for Analytical Chemistry. 4th Ed. New York: Ellis-Harwood, 1994. 115

27 Bard A J, Faulkner L R. Electrochemical Methods: Fundamental and Applications. New York: John Wiley \& Sons, 2001. 341

28 Lide D R. CRC Handbook of Chemistry and Physics. 82nd Ed. Boca Raton: CRC Press , 2001-2002 